\title{
Young Students' Reasoning About Ecosystems: the Role of Systems Thinking, Knowledge, Conceptions, and Representation
}

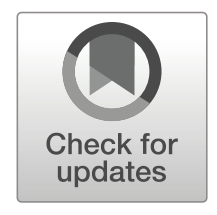

\author{
Sophia Mambrey ${ }^{1}$ (]) $\cdot$ Nico Schreiber ${ }^{2}$ ([) $\cdot$ Philipp Schmiemann ${ }^{1}$ (])
}

Published online: 27 February 2020

(C) The Author(s) 2020

\begin{abstract}
Regarding future ecological challenges, it is highly relevant for students to understand the processes within ecosystems and the effects of external influences on their conservation. Since ecosystems are complex, difficulties in learning are often examined from a systems thinking perspective. However, challenges also arise in other areas, particularly in the application of knowledge, conceptions, and exploration of conventionalized representations of ecosystems. Hence, we aim to determine the factors that influence reasoning about ecosystems and how they interact. We conducted a thinking-aloud study with 20 students aged between nine and 12 years while reviewing a food chain ecosystem. Our results indicated that students' reasoning was based on mixed reasoning originating from their systems thinking skills, knowledge, conceptions, and individual understanding of the ecosystem's representation. Further, they revealed that students referred to these factors according to the individual cognitive requirements of the systems thinking skills performed and independently of their age and systems thinking abilities. Additionally, students partially demonstrated complex levels of systems thinking, but their assumptions about systems elements and relationships did not support scientific conventions. Our results indicated that systems thinking was largely guided by systems-specific patterns, as basic assumptions about systems elements and relationships played a major role in reasoning about ecosystems at all levels of systems thinking. We assume that identifying systems characteristics with the identified factors of systems-specific knowledge, conceptions, and representations are an effective blueprint for investigating challenging patterns in students' understanding of ecosystems and advances knowledge on how systems properties influence students' reasoning during systems thinking.
\end{abstract}

Keywords Environmental education · Reasoning patterns · Systems thinking · Understanding of ecosystems

Sophia Mambrey

sophia.mambrey@uni-due.de

Extended author information available on the last page of the article 


\section{Introduction}

To achieve a sustainable future for all, the United Nations (2015) declared its Agenda for Sustainable Development to fight complex present and future social and environmental challenges. Especially regarding environmental education and sustainable development, students must understand complicated ecological issues like biodiversity loss. This is already addressed in international curricula at the primary school level, and integrated into advanced classes (e.g., Australian Curriculum, Assessment and Reporting Authority 2017; National Research Council 2013). Children learn how to identify ecosystems in their environment, analyze and predict their behavior, and understand why preserving ecosystems is highly relevant for the future. To facilitate this, international science standards emphasize analyzing the interplay of biotic and abiotic elements within ecosystems (Australian Curriculum, Assessment and Reporting Authority 2017; National Research Council 2013). Since ecosystems are complex, challenges in understanding them are often investigated from a systems thinking perspective.

However, Grotzer and Basca (2003) found that promoting systems thinking alone is insufficient for fostering students' ecosystems understanding. Research on ecosystems reasoning reveals challenging patterns not only from a systems thinking perspective, but also in dealing with knowledge, students' conceptions, and understanding subject-specific ecosystem representations. This paper investigates the factors that influence students' reasoning about ecological systems and how these factors interact. In this way, this study takes a step towards the conceptualization of cross-sectional systems thinking by investigating how systems properties influence students' reasoning during systems thinking.

\section{Reasoning About Ecosystems: a Systems Thinking Perspective}

In biology, systems thinking is heavily emphasized, as it supports scientists' daily work (Jacobson and Wilensky 2006). Systems thinking is necessary to solve ecological problems and challenges, which require considering and understanding many elements and their direct and indirect effects. As ecological issues like global warming and extinction are striking and ecosystems are part of science curricula in many countries, we see ecosystems as a relevant area for investigating and supporting students' systems thinking (United Nations 2015; National Research Council 2013; Australian Curriculum, Assessment and Reporting Authority 2017). When analyzing the effects of changes in an ecosystem, it is insufficient to look only at individual organisms. Rather, effects on the level of population interactions, such as predator-prey relationships, must be considered. This often involves analyzing indirect and cyclical effects like feedback loops, mediated consequences, and potential side effects. Frequently, these effects only gradually become apparent.

In science education research, systems thinking skills are defined as the ability to consider super-ordinated principles when understanding and predicting the interplay of elements in complex systems (Jacobson and Wilensky 2006). From a systems thinking perspective, students' ecosystems understanding has been investigated at all school levels (Ben Zvi Assaraf and Orion 2010; Evagorou et al. 2009; Hmelo-Silver and Pfeffer 2004; Hokayem and Gotwals 2016; Sweeney and Sterman 2000; Sweeney and Sterman 2007). Studies reveal that primary school students already engage in systems thinking with respect to ecosystems, especially monocausal reasoning (Fraune 2013; Hokayem and Gotwals 2016). Furthermore, feedback processes do not seem particularly noticeable for primary school students (Evagorou et al. 2009; Hokayem et al. 2014). 
On the one hand, frameworks in systems thinking research have focused on identifying and conceptualizing skills students need to understand complex systems (Mehren et al. 2018; Orion and Libarkin 2014; Sommer and Lücken 2010), and on the other hand they have emphasized how students develop their abilities in the sense of learning progression research (Hokayem and Gotwals 2016; Lee et al. 2019; Mehren et al. 2018). We rely on Mehren et al.'s (2018) framework, as it is a validated model for describing systems thinking, its levels, and the skills involved. This framework is developed to describe systems thinking in geography and comprises relevant findings on systems thinking from different fields of educational research like geography (Mehren et al. 2018), earth sciences (Ben Zvi Assaraf and Orion 2005, Ben Zvi Assaraf and Orion 2010; Batzri et al. 2015), and biology (Grotzer and Basca 2003; Hokayem and Gotwals 2016), involving research on systems thinking from major research groups e.g., Ben Zvi Assaraf and Orion (2005, 2010), Sommer and Lücken (2010), and Jacobson (2001). The research group of Mehren et al. (2018) was furthermore able to validate the framework in a large-scale assessment. We consider it appropriate and valid to use Mehren et al.'s (2018) framework to determine students' systems thinking skills in biology, as it incorporates and builds on the latest insights of systems thinking research.

The framework describes three skills used in systems thinking: systems organization, systems behavior, and system-adequate intention to act. Systems organization describes students' identification of essential systems components. In a forest, for example, students can identify foxes, birds, mice, and plants. To analyze systems behavior, students interrelate the relevant populations within an ecosystem and analyze how they interact, e.g., how a rising fox population influences other forest organisms. Students predict a system-adequate intention to act by identifying longterm effects, such as how current influences might impact a forest ecosystem in the future. These systems thinking skills can exist at different levels ranked by various causal relationships students consider in their reasoning, such as (a) monocausal relations in simple systems (Level 1), (b) linear relations in moderately cross-linked systems (Level 2), and (c) complex relations in highly cross-linked systems (Level 3) (Mehren et al. 2018).

\section{Young Students' Abilities in Systems Thinking}

A great variance exists between the conceptualizations, topics, and cohorts investigated in the field of systems thinking from primary to early secondary school (age between 8 and 12). Relevant studies reveal that students are able to identify essential components of complex systems (Ben Zvi Assaraf and Orion 2010, Sommer and Lücken 2010). Most children can identify interdependency between two components of a system. A deeper investigation of students' ability to analyze dynamic relations was conducted by Grotzer and Solis (2015), who examined spatial and attentional discontinuity in students' cause and effect reasoning in systems. Thereby, students across grades two, four, and six showed a prevalence for local cause and effect reasoning. They were unable to analyze the temporal and spatial delays at an abstract level. These results were supported by Hokayem and Gotwals (2016) and Hoakyem et al. (2014). Based on a qualitative approach, they investigated students' systems thinking reasoning skills from first up to fourth grade. It was identified that students' reasoning at primary school level was mainly based on anthropomorphic conceptions as well as everyday life experiences (practical reasoning). Furthermore, research reveals that students showed a major improvement in abilities through formal instruction at this early science education level (Ben Zvi Assaraf and Orion 2010; Sommer and Lücken 2010; Grotzer and Basca 2003), therefore indicating that there is great potential for learning systems thinking at the primary and early secondary school level. 


\section{Reasoning About Ecosystems: the Role of Knowledge, Conceptions, and Representations}

Besides students' systems thinking skills, other factors also influence their understanding of ecological systems. Here, we examine students' prior knowledge and conceptions, as well as the representation of the ecosystem itself.

\section{Knowledge}

Content-related knowledge seems beneficial for understanding ecosystems. Studies reveal that interventions, which emphasize content knowledge, lead to students' better understanding of more complex patterns in ecosystems (Grotzer and Basca 2003; Sommer and Lücken 2010). The impact of knowledge is also revealed when comparing novices' and experts' systems thinking. Research indicates that novices strongly focus on available, static components, whereas experts integrate structural and behavioral system components when analyzing ecosystems (Hmelo-Silver and Pfeffer 2004). It seems that "without systems-specific content knowledge, individuals appear to default to descriptive surface features" (Sweeney and Sterman 2007, p. 305) of ecosystems. Consequently, a deeper understanding of ecosystems involves integrating knowledge, which differs between novices and experts.

\section{Conceptions}

Acquiring new knowledge is not only influenced by learners' scientifically adequate prior understanding, but also by students' plausible (though scientifically incorrect) notions (Duit et al. 2013) that are seen as naïve, alternative, or as misconceptions. Following the approach presented by Gropengießer (e.g. Gropengießer 2007), individuals use metaphors to access and understand their environment by projecting a domain from everyday life onto another target domain they aim to access. This is especially relevant when the target domains cannot be experienced individually, such as interdependencies in food webs. Thereby, the degree of abstraction and complexity can vary from concepts expressed by the use of single terms, through propositions that express thinking constructs that relate to specific situations or domains, up to conceptions representing complex thinking figures within domains. Alternative conceptions represent an inadequate mapping of an experienced metaphor that is not suited to explain the target domain's structure. Therefore, evaluating students' language is particularly important to access their ways of thinking regarding a domain. We can assume that these ideas also influence reasoning about ecosystems. Findings supporting this assumption were revealed in a comparative international study by Barman and his colleagues (1995) who found that students demonstrate "specific misconceptions that impede their understanding of more complex information" from ecosystems (Barman et al. 1995, p. 781). Often, students cannot identify influences of a changing prey population on a predator population, and vice versa (American Association for the Advancement of Science 2019; Griffiths and Grant 1985). When referring to food availability, students use teleological reasoning patterns, imposing an intention on systems regulation. They indicate that populations exist to feed other populations (Leach et al. 1996, p. 113). The relationship between students' conceptions and systems thinking is particularly elucidated in a study by Hokayem and Gotwals (2016). They propose students' anthropomorphic and conceptual reasoning about ecological systems to be the lower anchor of a learning progression. Nevertheless, students' integrated reasoning patterns were based on their conceptions and complex levels of 
systems thinking and were rated as mixed-reasoning patterns. These findings indicated that students' conceptions could be relevant in all levels of systems thinking.

\section{Representations}

Science communication relies heavily on representation (Tsui and Treagust 2013). Understanding representations is an active and constructive cognitive procedure wherein a learner develops a mental model of representations by applying prior knowledge to representational features (Schnotz 2005). This is necessary for a deep understanding of representation and coherent reasoning. Hence, reasoning about subject-related representations, such as ecosystems, is influenced by learners' existing knowledge and ideas. Accordingly, representations can also influence reasoning about ecosystems.

Ecological systems are often presented as food webs or food chains. In ecology, a food web is a scientific conceptualization of an ecosystem (Begon et al. 2006), a model depicting interconnectedness and relationships to clarify the interplay of an ecosystem's elements. Food webs are highly conventionalized illustrations. In scientific representations, conventions express additional information for scientists that are challenging for students to understand (Tsui and Treagust 2013). Typical conventions in food webs represent populations through one animal. Furthermore, arrows are conventionalized as depicting energy flow (Begon et al. 2006). Consequently, they always point at the predator population. Arrows are often interpreted as "lives off," "produces," or "depends on" (Schollum 1983, p. 47), which contradicts scientific convention. Additionally, vertical organization of food webs by trophic levels (with predators on top) allows identification of depicted animals' relationships, although some might be unknown. Representations also include information on indirect or chain effects impacting entire ecosystems. For example, reducing the top predator population influences the population sizes of all other animals in the food web. Students show difficulties in integrating these mediated effects in their reasoning about ecosystems (American Association for the Advancement of Science 2019; Griffiths and Grant 1985). Based on these findings, representation seems to influence reasoning about ecosystems.

\section{Research Question}

Students' understanding of ecosystems has been investigated in many studies from a general systems thinking perspective. However, there seem to be additional factors (e.g., knowledge, conceptions, and conventionalized representations) that might impact reasoning about ecosystems. Hence, our study contributes to the existing literature by determining the factors that influence students' reasoning about ecosystems and how they interact.

\section{Method and Procedures}

\section{Participants and Data Collection}

Ecosystems are internationally relevant in curricula, from elementary to higher secondary classes. Existing studies on ecosystems understanding comprise various perspectives on teaching and learning, which enables the identification of relevant influences on the learning process and builds the basis for our comprehensive research approach. Based on a literature 
review, we expected that younger students' understanding of ecosystems would be influenced not only by systems thinking but also their personal experience and education. To capture the influences on students' understanding, we investigated systems thinking with students from primary to early secondary school. Investigations into students' systems thinking at this age reveal that most students show significant improvements in systems thinking performance through formal instruction (Ben-Zvi Assaraf and Orion 2010; Sommer and Lücken 2010; Grotzer and Basca 2003). Furthermore, at this early age, there is a great variance in students' abilities, comprising both students with no ambitions to use systems thinking in their reasoning as well as high performing students (Hokayem and Gotwals 2016; Ben-Zvi Assaraf and Orion 2010). Conclusively, we assume that there is a great potential for teaching and learning systems thinking in the school years from primary to early secondary school, which informed our choice to investigate students' systems thinking and development at this young age (BenZvi Assaraf and Orion 2010). To access a broad variance in students' understanding of ecosystems, we followed Hokayem and Gotwals's (2016) approach and performed a crosssectional design with $N=20$ students aged 9 to 12 years from a public primary and secondary school (Fig. 3 in Appendix). Our aim was not only to access students' systems thinking skills but also their cognitive activities while performing systems thinking. To gain insights on these cognitive activities of the meaning-making process, thinking-aloud processes are valid tools in educational and psychological research (Ericsson 2006; Ericsson and Simon 1998). Therefore, we asked participants to think aloud while answering a questionnaire on ecosystems. Participants explained why they considered certain answer options right or wrong. The questions aimed to access students' intuitive cognitive activities while undertaking systems thinking. Therefore, no intervention on ecosystems was conducted beforehand by the researchers.

The questionnaire included 14 questions on systems thinking. To ensure validity, it was developed based on Mehren et al.'s (2018) systems thinking model. Each question (8 on systems organization, 3 on systems behavior, and 3 on systems-adequate intention to act) addressed one systems thinking skill and included a question, a representation of an ecosystem (food web), and three possible answers (see Fig. 1 for sample item and Table 1 in Appendix for all items).

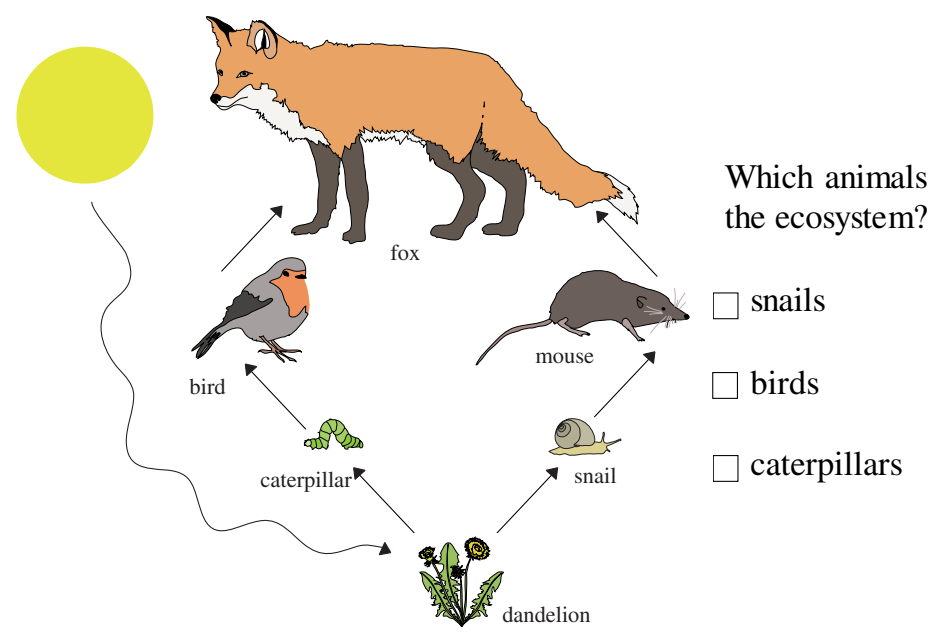

Fig. 1 Sample item following the framework of Mehren et al. (2018): Systems organization at a monocausal level (Level 1) 
We used the questionnaire to access students' abilities as Grotzer and Solis's study (2015) appeared to show that although students infrequently reported complex statements regarding, for example, distal explanations for dynamic interactions, they chose them when presented to them. Therefore, to access students' cognition, we prompted their systems thinking skills by presenting different answer options to them in a questionnaire and analyzed the cognitive processes performed while reasoning. Furthermore, the questionnaire simultaneously reduced the reading skills required. Students could always use simple reasoning but were encouraged to apply complex thinking processes. This should have engaged students to also consider indirect or complex effects. Students were introduced to the method of thinking aloud and then trained with a sample test item. During the training, students were requested to explain why they considered certain answer options to be right or wrong and give insights into their reasoning process. Thinking aloud took up to $40 \mathrm{~min}$ for each student and was recorded by a voice recorder. All statements were transcribed.

\section{Data Analysis}

To analyze students' transcribed thinking-aloud protocols, we developed a theory-based coding frame following Schreier (2012) (Table 2 in Appendix), which included systems thinking, knowledge, conceptions, and representations as the main categories. First, we assigned the systems thinking skill related to the skill addressed in the questionnaire. Then, we analyzed the underlying patterns of complexity in the students' statements according to the progress levels of Mehren et al.'s (2018) systems thinking model. If several statements were made in succession, the maximum linkage was assumed to indicate the progression level of systems thinking. When students expressed correct statements on biological content, we categorized their knowledge. When they used ideas based on everyday experiences or from classes that were inconsistent with a scientific perspective, we coded their conceptions. Statements referring to system presentation were coded as representations. To ensure the reliability of the coding, in the first step, two scientists independent of the study worked separately to categorize all the recorded explanations. In the second step, both raters discussed differences in coding until an agreement was reached (Schreier 2012; Markauskaite et al. 2017). Hence, our results represent the agreed coding of both scientists.

\section{Ethical Considerations}

All students and their parents were informed in advance about the aim and the procedures of the study, and that participation was voluntary. They all consented to participate. To protect privacy, and following data protection restrictions, data analyses were performed with anonymized transcripts and no additional data about the participants were collected, except their age and the thinking-aloud protocols. Therefore, gender and differences in skills regarding gender cannot be reported.

\section{Results}

We coded 215 students' statements referring to systems thinking $(42.8 \%, 92)$, students' knowledge $(20.8 \%, 45)$, students' misconceptions $(19.1 \%, 41)$, and representational features $(17.1 \%, 37)$. In the following sections, we present each category's coding and results (for details, see Table 2 in Appendix), and we provide an overview of the students' abilities and reasoning profiles according to the different systems thinking skills. 


\section{Systems Thinking}

Regarding identifying systems organization, students could reason systemically at all levels of systems thinking. Students' statements showed monocausal reasoning patterns (Level 1) by identifying one element acting on another, e.g., "The mouse eats the snail" (3029). They addressed linear relations (Level 2) when identifying element A acting on element B and element B acting on element C, e.g., "The snail eats the dandelion and the mouse eats the snail" (5011). A complex reasoning pattern was revealed (Level 3) when more than three elements were involved and demonstrated at least one connection point where the interdependence of more than three elements occurred (A acted on B and A acted on C), e.g., "The sun makes the dandelion grow. The snail or caterpillar eats the dandelion. The mouse or bird eats the snail or caterpillar. The fox eats the bird or mouse" (5011).

All statements presented regarding the systems organization skill indicated that students' reasoning was based on descriptive patterns referring to single animals in the ecosystem rather than populations. They did not seem to develop an abstract model of ecosystems, but described individual actions depicted at different complexity levels.

When analyzing systems behavior, students identified feeding relationships between the ecosystem elements. However, these also remained at an individual level. Students recognized that intervention on one animal in the ecosystem also affected others. These effects were analyzed at different complexity levels, ranging from monocausal to complex. A complex analysis was revealed (Level 3) in the statement: "All animals are poisoned and get sick. The snail and caterpillar eat the poisoned dandelion. The bird and mouse eat the caterpillar and snail, which are also poisoned, and the fox eats the bird and mouse, accordingly" (6004). The student identified complex interrelations between animals in the ecosystem by explaining why single animals were poisoned. As shown in the systems behavior example, the analyzed effects mainly moved in one direction: from the starting point to the top predator. Thus, students did not mention feedback loop processes.

Regarding system-adequate intention to act, students need to predict how an intervention today influences the ecosystem in a future state. Students tend to choose direct solutions by predicting consequences mainly on a monocausal level, as stated in the following sentence regarding the question of how one could achieve having fewer caterpillars in gardens: "You could poison the caterpillars because they eat all the salad" (3034). To achieve a higher level of systems thinking, the student needs to consider further effects on other animals in the ecosystem and has to integrate a prospective view in their analysis. This reveals that students described complex effects but did not recognize prospective regulatory processes like feedback loops. Rather, it was indicated that intervention by humans, in general, negatively influenced the food web.

\section{Knowledge}

The statements analyzed showed a variety of factual knowledge. Regarding systems organization, students recognized individual animals and explained the knowledge they associated with them. To answer the questions, students frequently referred to their prior knowledge (73.2\%, 33 of 45) instead of the elements and relationships in the food web. Regarding which animal was eaten by another animal, Student 4001 reasoned: "I say the snail because it [...] is not a predator and has $[\ldots]$ little protection $[\ldots .$.$] ."$

Students demonstrated high and low levels of systems behavior analysis $(22.1 \%, 10$ of 45$)$. The question, "Poisonous garbage is dumped in the ecosystem. What will happen to its animals?" was 
asked to understand their perspectives on animals' relationships. They applied their prior knowledge of how poison makes animals sick to their answers. Student 3029, for example, used this knowledge to explain that "All animals will be affected because poison makes animals sick" (3029). In contrast, Student 6004 applied this knowledge and added a complex analysis of systems relationships regarding how poisoning would affect all animals: "All animals are poisoned and get sick. The snail and caterpillar eat the poisoned dandelion. The bird and mouse eat the caterpillar and snail, which are poisoned again, and the fox eats the bird and mouse, accordingly."

Concerning the system-adequate intention to act skill, students barely used their knowledge (4.3\%, 2 of 45). Rather, they imagined potential scenarios that related more to their conceptions than their knowledge, as presented in the "Results" section regarding conceptions. Only two students used their knowledge when predicting a system-adequate intention to act. Thereby, they supported their assumption regarding future system states based on their knowledge.

\section{Students' Conceptions}

Students' conceptions were mostly very individualized ideas about nature. Based on their conceptions, students identified systems organization $(24.4 \%, 10$ of 41$)$ by explaining the relationship between the ecosystem's elements. Student 5031 responded, "The snail eats the dandelion and mouse eats the snail. That means the dandelion is in the snail and the mouse eats the snail with the dandelion in it."

Students imagined that if an animal ate a plant, a small part of that plant remained in the consumer. If this animal was eaten by another animal, it would contain parts of all that had been consumed before. We supposed that the student followed the idea of a container scheme (Niebert et al. 2012). Higher concepts of digestion and energy transfer were not mentioned. As presented in the example, the student considered the animals presented in the food web on an individual level and not on a population level, as in the scientific understanding.

Students often analyzed systems behavior $(26.7 \%, 11$ of 41$)$ from an anthropomorphic perspective (Hokayem and Gotwals 2016). They stated, "Snails are important [and] do clean nature" (5028) or that animals could actively think "[...] the animals think that [...]" (4005). Thereby, students gave animals human characteristics or behavior.

Most conceptions were mentioned regarding the system-adequate intention to act (48.8\%, 20 of 41). Students frequently referred to the balance of nature concept. Student 5031 stated, "There must always be a certain balance in nature." Following students' conceptions, influences on the ecosystem (such as human intervention) should aim at not disturbing the ecosystem's balance.

Student 6003: "The fox eats birds and mice in the meadow and [when one decreases the fox population] there is no one [to eat the mice and birds], who become too numerous. Then, people come and do not want [mice and birds] anymore, so the whole [food web] is broken."

Students demonstrated a complex analysis of the ecosystem. Nevertheless, this student evaluated intervention by humans as destructive to the ecosystem. Students used their conceptions in all skills and levels of understanding complex ecosystems, most frequently regarding their prediction of a system-adequate intention to act.

\section{Representation}

The majority of statements made regarding the representation of the food web were coded when identifying systems organization $(97.3 \%$, 36 of 37). When thinking aloud, students referred to the representation to confirm their reasoning. However, they also reported 
misunderstandings regarding scientific conventions used in the food web, like the meaning of arrows or the implicit integration of indirect effects. Various meanings were perceived, e.g., "equals" vs. "to become," or arrows were misinterpreted by assuming "B eats A," as in "snail eats bird," instead of "A eats B," as in "bird eats snail." These assumptions regarding representational features affected the understanding of interrelationships between ecosystem elements. Additionally, students negated indirect relationships because they stated there was "no connection between the animals in the food web" (5001); "I would assume this connection, but there is no arrow between these animals in the picture" (4005); and "I do not see any connection between these animals" (4004). It is apparent that students believed that there were no relationships because indirect relationships were not explicitly indicated in the representation. Regarding the conventionalized representation of populations by single animals, students frequently reasoned at the individual level. There did not seem to be an abstract model of populations interacting in the ecosystem, rather than individuals. It could be observed that students did not detach themselves from the concrete, observable contents of the representation. Consequently, difficulties arose when understanding scientific conventions, such as arrows, indirect effects, or interrelationships at a population rather than individual level.

\section{Development of Systems Thinking Skills}

In the following section in Fig. 2, we present an overview of students' abilities and reasoning profiles regarding the different systems thinking skills by reporting the maximum level of

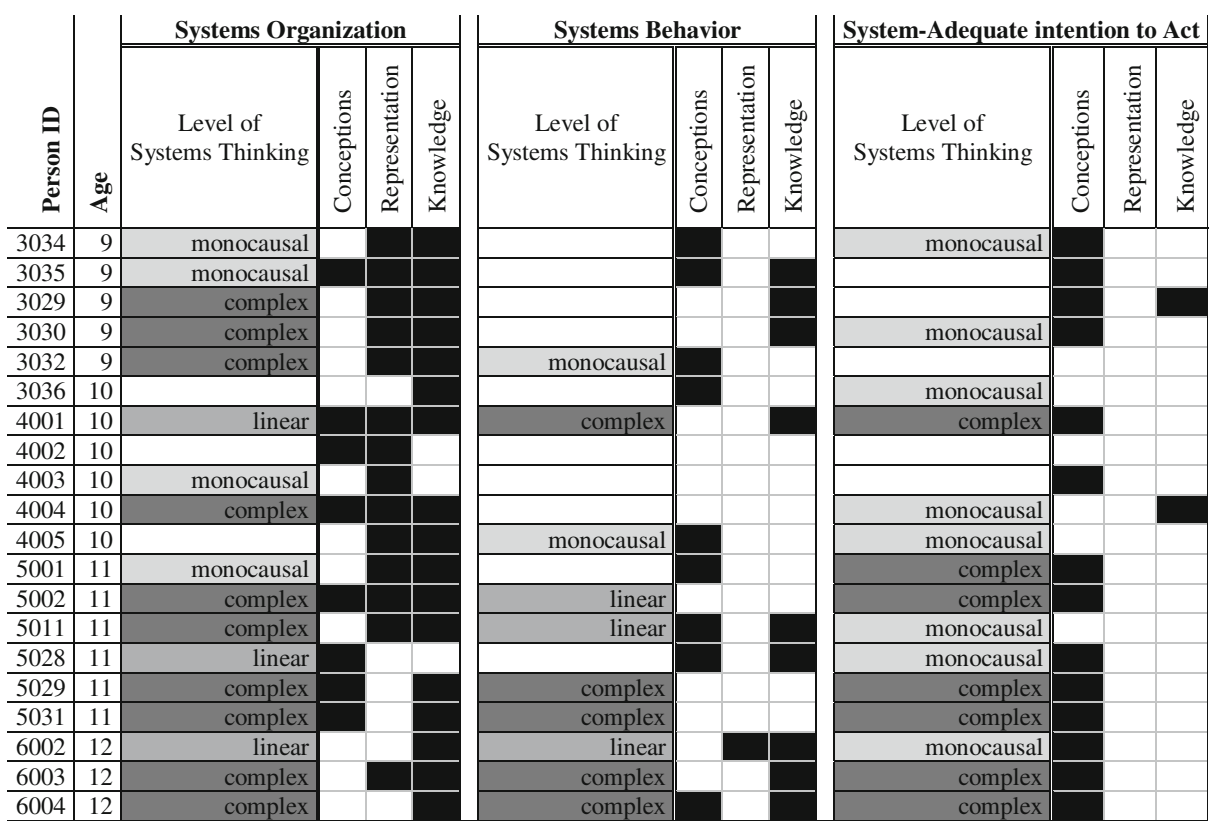

Fig. 2 Summary chart of the reasoning profiles students used regarding the different systems thinking skills identified following Mehren et al (2018). Regarding each skill of systems thinking, the maximum complexity of systems thinking skills observed for each student is listed. If a student referred to either conceptions, representation, or their knowledge in the reasoning patterns, this is displayed with a black box. If no statement was made regarding systems thinking or further reasoning patterns the figure shows a blank space. 
systems thinking and further reasoning patterns used by the students per skill. In the figure, the three main columns represent the main systems thinking skills following the model by Mehren et al. (2018). Each line stands for one student ordered by age, starting with the youngest. For each main column, we represent the highest reached level of systems thinking by the student. Furthermore, the black box represents whether the students used reasoning patterns regarding their conceptions, representation, or knowledge. This provides an overview of the students' reasoning patterns development according to their age.

It reveals that systems thinking performance improved with age, as the number of relationships and elements considered rose in students' thinking-aloud protocols. Students at a younger age showed little reasoning based on systems analysis, although they showed a higher frequency of ability regarding the skills systems behavior and system-adequate intention to act. Nevertheless, some individual students were also able to show complex reasoning patterns at a young age. A matter of particular interest can be identified in the reasoning patterns of students regarding the diverging systems thinking skills. When they reason on systems organization, they frequently refer to the given representation and their knowledge, whereas, when reasoning on systems behavior, students refer to their conceptions and knowledge. It can be further identified that while addressing the systems-adequate intention to act, students address mainly their conceptions. Thereby, the reasoning patterns used do not vary substantially within the age cohort.

\section{Discussion}

Conserving ecosystems are one of our future's central challenges (United Nations 2015). Hence, we aim to investigate how students reason regarding ecosystems and which factors influence their reasoning. Mehren et al.'s (2018) framework was revealed to be well-suited to analyze students' systems thinking skills, as we could evaluate all skills and levels of systems thinking. The analyzed data provided information on the increasing complexity of students' systems thinking skill in relation to their age, while revealing that students based their reasoning not only on systems thinking, but also on their knowledge, conceptions, and representations about the ecosystem. It was identified that specific reasoning patterns occur due to the systems thinking skill performed, independent of students' age.

\section{Systems Organization}

Students showed frequent reasoning patterns in relation to the representation of a complex system and their individual knowledge. Conclusively, when performing systems organization, students interact with the representation to identify relevant information within the system. Visual representations play a major role in scientific communication (Tsui and Treagust 2013). Especially in the visualizations of complex ecological systems, the degree of abstraction varies widely (Roth and Pozzer-Ardenghi 2013), and students need to understand a wide range of representations like food chains, food webs, or computational models. Following Schnotz's (2005) approach, students integrated their knowledge and conceptions to understand the food web representations. Our results showed that a lack of knowledge regarding conventionalized representational features, not ecosystems in general, prevented a deeper understanding of the ecosystem when identifying systems organization. They demonstrated difficulties decoding the conventions, showing misunderstandings when identifying indirect effects (Griffiths and Grant 1985, AAAS 2019). Without decoding the conventionalized image, identification of the system 
organization remained superficial and strongly oriented on patterns of representation, which was confirmed by results from earlier studies (Sweeney and Sterman 2007).

\section{Systems Behavior}

Students applied their knowledge and conceptions to analyze systems behavior. Qualitative analysis reveals that in this process, students could analyze a complex number of elements and relations but based their analysis on rather superficial assumptions about systems relationships, which originate from fragmented individual knowledge and misconceptions. According to Piaget (1966), younger participants' perceptions are still strongly led by observable phenomena. Thus, knowledge and conceptions in our study were particularly specific to the given animals of the presented ecosystem. When analyzing systems behavior, students revealed that their ecosystem understanding was based on coexistence of individuals, rather than populations. This missing abstraction of the given content is in line with earlier studies, where students based their reasoning on their direct experience or environment (Hokayem and Gotwals 2016; Grotzer and Solis 2015) or observable systems patterns (Hmelo-Silver and Pfeffer 2004). Our research indicates that this is not only a phenomenon that affects young students' systems thinking since with knowledge or conceptions concerning single feeding relationships students were unable to overcome a unidirectional and very individual understanding of the elements and relationships presented in the ecosystem (Grotzer and Solis 2015).

\section{System-adequate Intention to Act}

When students predicted a system-adequate intention to act, they frequently referred to their conceptions. Students overestimated the scope of ecosystem interventions, as their understanding was led by the idea of single animals depending on each other rather than populations. Since students did not exhibit knowledge of mechanisms, such as feedback loop processes or indirect effects, we suspected that predicting interventions' impacts on the ecosystem over time were difficult. We assumed that because they did not have knowledge of typical process patterns in the ecosystem, their arguments were based on their conceptions.

We conceptualized knowledge and misconceptions as the opposite ends of a continuum, from scientifically correct knowledge to plausible but scientifically incorrect misconceptions. We know that this does not necessarily imply two diverging cognitive procedures, but rather, contrasting factors affecting ecosystem understanding. Thus, it may be possible that students' reasoning regarding the system-adequate intention to act could also be affected by their knowledge, if available; this was also evident in our study. Nevertheless, misconceptions are often resistant to change and firmly held by individuals (Duit et al. 2013; Duit and Treagust 2003). First signs on the robustness of students' conceptions in the domain of ecosystem analysis were revealed in the study of Reiner and Eilam (2001), where ninth-grade students' conceptions changed after instruction, but their thinking figures, for example ontological beliefs, did not. Especially in young students, there is a strong belief in conceptions like the balance of nature (Ergazaki and Andriotou 2010) or container schemes (Niebert et al. 2012). We also assume that predicting future systems settings involves not only the application of knowledge but also creativity. Therefore, students might not only ponder which scenario is the most likely to happen according to their knowledge but think of potential future scenarios based on their imagination. It remains to be investigated whether conceptions influence students' systems thinking only at an early age, or in higher grades too. 


\section{Explanations of Mixed-factor Reasoning}

Our study revealed two major findings on mixed-factor reasoning about ecosystems. First, students referred to factors influencing the individual cognitive requirements of the systems thinking skills performed independently of their abilities in systems thinking or their age. Second, the complexity of students' systems thinking was independent of their basic assumptions on systems patterns and relationships, indicating that just because a statement was complex, it did not have to be led by scientific assumptions regarding the system. Studies often conclude that young students are unable to engage in complex systems thinking (Hokayem and Gotwals 2016; Sommer and Lücken 2010). However, we suggested that they might lack the basic knowledge to argue scientifically, which was found to be systemically correct.

The identification of mixed-factor reasoning aligned with findings from Hokayem and Gotwals (2016) but contradicted their assumption of a natural evolutionary learning progression, which characterizes reasoning based on conceptions as low-level reasoning and complex reasoning patterns as the highest level. Rather than conceptualizing a linear learning progression concerning systems thinking in ecosystems with absolute levels, our analyses indicated that factors influencing students' reasoning seemed skill-specific and independent of students' systems thinking abilities. Furthermore, most of the systems thinking framework confounds the assumption that complex systems thinking only occurs at correct basic assumptions on systems relations, which we can refute with our study's results (Hokayem and Gotwals 2016; Mehren et al. 2018).

\section{Limitations}

Our study has some limitations. In our study, we aimed to determine the factors that particularly influence students' reasoning. To do so, we used one specific ecosystem in our questionnaire; hence, our findings are limited to this system for now. Students could investigate this ecosystem over time, which additionally led to constant use of the same system complexity. This could have contributed to the fact that students did not reconsider their basic assumptions about the ecosystem. In a further study, this limitation could be addressed by having students analyze a variety of ecosystems. We developed the presented ecosystem according to scientific conventions, which meant that elements were labeled as singular. This could have enhanced reasoning at the individual level. Hence, investigating whether plural labels promote thinking concerning populations would be worthwhile. However, since this did not correspond to scientific conventions, we did not implement it in our study. A further limitation could be that students' reasoning did not always correspond to our investigation's focus, which was, of course, age-appropriate for the young participants of our study. However, this explains why the number of statements rated was lower than the potential number of reasoning patterns fostered by the questionnaire. Finally, our results represent students' systems thinking "as it is" to provide an ecologically valid description. This implies that the particular sources of students' skills, for example, science lessons or out of school learning, need to be subjected to further investigations.

\section{Implications and Outlook}

With this thinking-aloud study, we intended to investigate factors influencing students' reasoning about ecological systems from multiple perspectives. Our results add to what is 
already known on systems thinking, by showing that systems thinking is highly guided by systems-specific patterns, as basic assumptions on systems elements and relationships heavily impacted reasoning about ecosystems at all levels of systems thinking. This should be considered when nurturing students' systems thinking skills across grades and topics, as we discovered that students may be able to consider a complex number of elements and relations in their assumptions on a complex system, but their lack of knowledge or their conceptions foster incorrect conclusions on the interdependencies between elements. Furthermore, our study contributes to the field, by identifying the significant relevance of focusing on representation formats, students' knowledge, and students' conceptions when teaching systems thinking. We assume that identifying systems characteristics within the factors of systemsspecific knowledge, conceptions, and representations are an effective blueprint for further research, as it reveals challenging patterns in students' ecosystem understanding, which is highly relevant for the teaching process. Science educators should be aware that the complexity of systems thinking and the correctness of a statement do not necessarily correlate. Rather, students may show complex thinking processes that underlie conclusions that are based on conceptions or lack of content knowledge. Furthermore, the instruction given to the students significantly influences their cognitive activities. As diverse systems thinking skills demand distinct cognitive activities and potentially different instruction, future research could address whether skill-specific foci of instruction regarding systems thinking can significantly improve students' reasoning about ecosystems or even reach beyond ecosystems understanding and be generalized to a common tool for improving systems thinking. Our research also guides the investigation and conceptualization of a unified framework for systems thinking across fields and lays the basis for advancing tools for developing systems thinking across topics and grades, which is highly relevant for the implementation of systems thinking as a core skill in science curricula (National Research Council 2013; Australian Curriculum, Assessment and Reporting Authority 2017). Ultimately, we assume that our results particularly advance research on systems thinking, as they indicate that conceptualizing the intersection of systems thinking skills requires consideration of systems and skill-specifics.

Acknowledgments We would like to thank Professor Armin Rempfler from the University of Teacher Education Luzern for supporting us in the item development of this study. Furthermore, we would like to thank our student research assistants, Johannes Wolters (for transcription) and Kristian Frey (for transcription and coding of the thinking aloud protocols). Additionally, we thank the IZfB for its financial support regarding the professional editing service.

Funding Information Open Access funding provided by Projekt DEAL.

\section{Compliance with Ethical Standards}

This project was conducted under the auspices of the graduate school for primary education "SUSe I" of the University of Duisburg-Essen and was financially supported by the Ministry of Innovation, Science and Research of the State of North Rhine-Westphalia. We contracted professional editing services by Editage, financially supported by the IZfB (Interdisciplinary Centre for Educational Research) of the University of Duisburg-Essen. Any opinions, findings, conclusions, or recommendations expressed in this publication are those of the authors and do not necessarily reflect the views of the funder. We confirm that there are no potential conflicts arising from these arrangements. 


\section{Appendix}

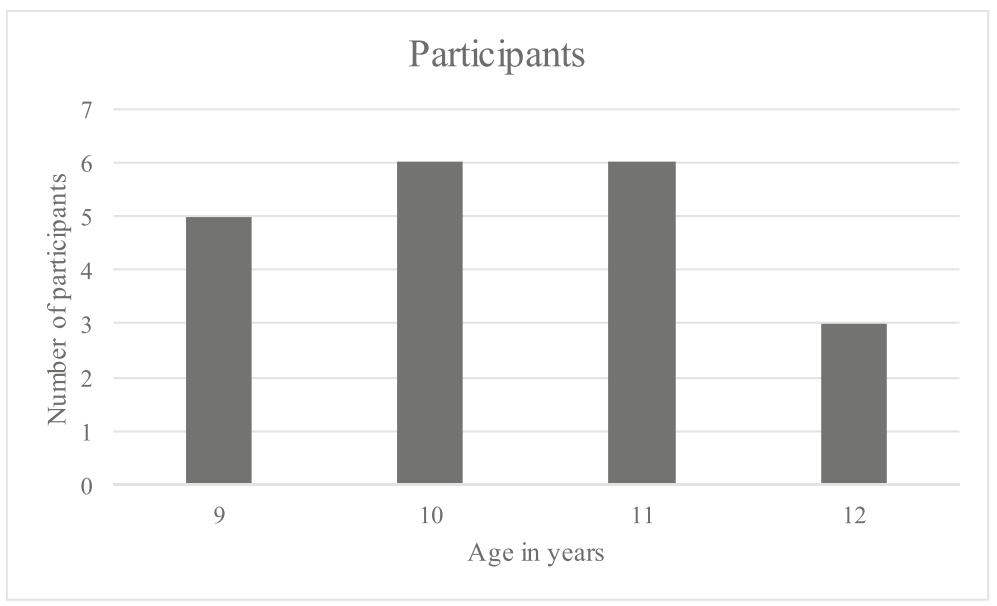

Fig. 3 Sample number of participants by age

Table 1 Overview on questionnaire and item construction. In the table, the items are displayed in an overview chart. All items refer to the presented figure underneath. The students were presented an age-appropriate format of the questionnaire. To access students reasoning on systems thinking, items 1-6 are developed in a multiplechoice (MC) format. The addressed elements and relations in these items are always related to one level of the systems thinking model by Mehren et al. (2018). Items 7-14 are developed in an ordered multiple-choice (OMC) format. In these items, all distractors present one level of a systems thinking skill of the systems thinking framework. This allows the condensed representation of a variety of response options and thereby a timeeconomic survey method. We have always applied the OMC format when it matched best to the skill addressed

System organization:

Elements in the system and their relations can be identified (Items 1-6). Students identify systems elements and its borders (Items 7-8).

No. Question

\section{Answer Options}

1. Which animal in the food web eats another animal? A) Snail

B) Bird

C) Caterpillar

2. Which animal in the food web is being eaten by

A) Fox another animal?

B) Sun

C) Snail

3. A predator is an animal that eats other animals (the prey). Which relationship between predator and prey is correct?

A) Snail (prey)-mouse (predator)

B) Fox (prey)-bird (predator)

C) Caterpillar (prey)-snail (predator)

4. Which relationship is displayed in the food web?

A) Sun-> caterpillar

B) Snail-> bird 
Table 1 (continued)

5. Which relationship is displayed in the food web?

6. Which relationship is displayed in the food web?

7 Ducks eat snails.

Are ducks part of the depicted food web?

8. Imagine a fire breaks out. Is it part of the food web?

System behavior

Students analyze the relation between system elements. They analyze the dependence of systems elements on each other (Items 9-11).

9. Imagine people mowing the lawn very often. Thereby the blossom of a dandelion is being cut off. What happens to the dandelion in the course of time?

10. Imagine all snails are being collected from the meadow. On which aspect would it have an impact on?

11. Toxic waste is being stored on a part of the meadow. What happens consequently?

System-adequate intention to act

Students predict the potential development of the system over time (Items 12-14).

12. Houses are being built on the meadow. The meadow is being destroyed.

On which aspect would it have an impact on?

13. People want to expel the fox.

Does it make sense?

14. People want fewer caterpillars within their gardens. How could they achieve that?
C) Caterpillar- $>$ mouse

A) Dandelion- $>$ mouse

B) Caterpillar- $>$ mouse

C) Snail- $>$ bird

A) Sun- $>$ fox

B) Caterpillar- $>$ mouse

C) Bird-> Snail

A) Ducks are always part of the food web.

B) Ducks are partially part of the food web. They sometimes occur on meadows.

C) Ducks are not part of the food web. They do not occur within the presented food web.

A) If a fire breaks out on the meadow, it will destroy the plants. Thus, the fire is part of the food web.

B) If a fire breaks out on the meadow, it will destroy plants and will hurt animals. Thus, the fire is part of the food web.

C) If a fire breaks out on the meadow, it will damage plants and animals only for a short time. Thus, the fire is not part of the food web.

A) All blossoms will regrow more quickly afterwards.

B) Some blossoms will grow low. These blossoms will not be cut off by the lawnmower.

C) The small dandelion has advantages. It will not be cut off that often. Same applies for its offspring.

A) It only damages the mice living on the meadow.

B) It benefits the caterpillars.

C) It could damage all animals, including the fox.

A) Only dandelions nearby the waste will be poisoned.

B) The dandelions and the animals eating them will be poisoned.

C) All animals and plants on the meadow will be poisoned.

A) The dandelion is not able to grow anymore. However, the animals are not being damaged by the houses.

B) It can have an impact on the fox.

C) It has an impact on all animals and all plants within the food web. However, you cannot predict the exact changes.

A) It would be good. People then would not be afraid of foxes anymore.

B) It would be good because foxes would not eat mice and birds anymore.

C) It would be bad because there would be too many mice and birds.

A) One could poison the caterpillars.

B) One could remove the dandelions.

C) One could build more nesting sites for birds. 
Table 2 Results: category system, sample categorization, and number of statements. * Deviations from the $100 \%$ mark occur due to rounding of the relative number of statements

\begin{tabular}{|c|c|c|c|}
\hline Categories & Example statements & $\begin{array}{l}\text { Total } \\
\text { number of } \\
\text { statements }\end{array}$ & $\begin{array}{l}\text { Relative number } \\
\text { of statements in } \\
\text { percentages }\end{array}$ \\
\hline 1. Systems thinking & & 92 & $42.8 \%$ \\
\hline 1.1. System identification & & 56 & $60.9 \%$ (of 92 ) \\
\hline 1.1.1. Monocausal & "The mouse eats the snail." & 22 & $39.3 \%$ (of 56$)$ \\
\hline 1.1.2. Linear & $\begin{array}{l}\text { "The snail eats the dandelion and the } \\
\text { mouse eats the snail." }\end{array}$ & 17 & $30.4 \%($ of 56$)$ \\
\hline 1.1.3. Complex & $\begin{array}{l}\text { "The sun makes the dandelion grow. The } \\
\text { snail or caterpillar eats the dandelion. } \\
\text { The mouse or bird eats the snail or } \\
\text { caterpillar. The fox eats the bird or } \\
\text { mouse." }\end{array}$ & 17 & $30.4 \%($ of 56$)$ \\
\hline 1.2. System analysis & & 14 & $15.1 \%$ (of 92$)$ \\
\hline 1.2.1. Monocausal & $\begin{array}{l}\text { "When many caterpillars exist, many } \\
\text { birds will come because they will } \\
\text { have ample food." }\end{array}$ & 4 & $28.6 \%($ of 14$)$ \\
\hline 1.2.2. Linear & $\begin{array}{l}\text { "Birds have ample food when many } \\
\text { caterpillars exist. There will be more } \\
\text { birds. If there are more birds, there } \\
\text { will be more foxes." }\end{array}$ & 4 & $28.6 \%$ (of 14$)$ \\
\hline 1.2.3. Complex & $\begin{array}{l}\text { "The dandelion is the food web's } \\
\text { foundation. If it disappears, snails and } \\
\text { caterpillars will not have food and will } \\
\text { become extinct. Mice and snails also } \\
\text { will not have food and will become } \\
\text { extinct, and the fox will be } \\
\text { endangered, too." }\end{array}$ & 6 & $42.9 \%$ (of 14$)$ \\
\hline 1.3. System-adequate Intention to Act & & 22 & $23.9 .1 \%$ (of 92) \\
\hline 1.3.1. Monocausal & $\begin{array}{l}\text { "You could poison the caterpillars, } \\
\text { because they eat all the salad." }\end{array}$ & 14 & $63.5 \%($ of 22$)$ \\
\hline 1.3.2. Linear & $\begin{array}{l}\text { "You could make more nesting sites for } \\
\text { birds because they eat the caterpillars } \\
\text { and the caterpillars eat the } \\
\text { dandelions." }\end{array}$ & 1 & $4.4 \%$ (of 22 ) \\
\hline 1.3.3. Complex & $\begin{array}{l}\text { "Destroying the lawn by building houses } \\
\text { would affect all plants and animals. } \\
\text { The dandelion would be destroyed, } \\
\text { and the caterpillars, snails, and foxes } \\
\text { would not have food. }\end{array}$ & 7 & $31.7 \%($ of 22$)$ \\
\hline 2. Students' conceptions & $\begin{array}{l}\text { "Snails are important; they clean nature"; } \\
\text { "There must always be a certain } \\
\text { balance in nature;" "Mice are not very } \\
\text { nice animals because they steal food." }\end{array}$ & 41 & $19.1 \%$ \\
\hline 3. Biological knowledge & "Plants need water to grow." & 45 & $20.8 \%$ \\
\hline 4. Representational features & $\begin{array}{l}\text { "Because here in the representation, you } \\
\text { can see that ..." }\end{array}$ & 37 & $17.1 \%$ \\
\hline$\sum$ Overall categorized statements & & 215 & $99.8 \% *$ \\
\hline
\end{tabular}


Open Access This article is licensed under a Creative Commons Attribution 4.0 International License, which permits use, sharing, adaptation, distribution and reproduction in any medium or format, as long as you give appropriate credit to the original author(s) and the source, provide a link to the Creative Commons licence, and indicate if changes were made. The images or other third party material in this article are included in the article's Creative Commons licence, unless indicated otherwise in a credit line to the material. If material is not included in the article's Creative Commons licence and your intended use is not permitted by statutory regulation or exceeds the permitted use, you will need to obtain permission directly from the copyright holder. To view a copy of this licence, visit http://creativecommons.org/licenses/by/4.0/.

\section{References}

American Association for the Advancement of Science (AAAS). (2019). Interdependence in ecosystems. http://assessment.aaas.org/topics/1/IE\#/0. Accessed 27 March 2019.

Australian Curriculum, Assessment and Reporting Authority. (2017). Australian curriculum: F-10 curriculum: Science. https://www.australiancurriculum.edu.au/f-10-curriculum/science/. Accessed 22 March 2019.

Barman, C. R., Griffiths, A. K., \& Okebukola, P. A. (1995). High school students' concepts regarding food chains and food webs: a multinational study. International Journal of Science Education, 17(6), 775-782.

Batzri, O., Assaraf, O. B. Z., Cohen, C., \& Orion, N. (2015). Understanding the earth systems: expressions of dynamic and cyclic thinking among university students. Journal of Science Education and Technology, 24, 761-775. https://doi.org/10.1007/s10956-015-9562-8.

Begon, M., Townsend, C. R., \& Harper, J. L. (Eds.). (2006). From individuals to ecosystems (4th ed.). Oxford: Blackwell Publishing.

Ben Zvi Assaraf, O., \& Orion, N. (2005). Development of system thinking skills in the context of earth system education. Journal of Research in Science Teaching, 42(5), 518-560.

Ben Zvi Assaraf, O., \& Orion, N. (2010). System thinking skills at the elementary school level. Journal of Research in Science Teaching, 47, 540-563.

Duit, R., \& Treagust, D. F. (2003). Conceptual change: a powerful framework for improving science teaching and learning. International Journal of Science Education, 25, 671-688.

Duit, R., Treagust, D., \& Widodo, A. (2013). Teaching science for conceptual change: theory and practice. In S. Vosniadou (Ed.), International handbook of research on conceptual change (pp. 629-646). New York: Routledge.

Ergazaki, M., \& Andriotou, E. (2010). From "forest fires" and "hunting" to disturbing "habitats" and "food chains": do young children come up with any ecological interpretations of human interventions within a forest? Research in Science Education, 40(2), 187-201.

Ericsson, K. A. (2006). Protocol analysis and expert thought: concurrent verbalizations of thinking during experts' performance on representative tasks. In K. A. Ericsson, N. Charness, R. R. Hoffman, \& P. J. Feltovich (Eds.), The Cambridge handbook of expertise and expert performance (pp. 223-241). New York: Cambridge University Press.

Ericsson, K. A., \& Simon, H. A. (1998). How to study thinking in everyday life: contrasting think-aloud protocols with descriptions and explanations of thinking. Mind, Culture, and Activity, 5(3), 178-186.

Evagorou, M., Korfiatis, K., Nicolaou, C., \& Constantinou, C. (2009). An investigation of the potential of interactive simulations for developing system thinking skills in elementary school: a case study with fifthgraders and sixth-graders. International Journal of Science Education, 31(5), 655-674.

Fraune, K. (2013). Modeling system thinking - assessment, structure validation and development. (PhD. dissertation). Christian-Albrechts-Universität zu Kiel, Kiel.

Griffiths, A. K., \& Grant, B. A. (1985). High school students' understanding of food webs: identification of a learning hierarchy and related misconceptions. Journal of Research in Science Teaching, 22(5), 421-436.

Gropengießer, H. (2007). Theorie des erfahrungsbasierten Verstehens [theory of experiential understanding]. In D. Krüger \& H. Vogt (Eds.), Theorien in der biologiedidaktischen Forschung: Ein Handbuch für Lehramtsstudenten und Doktoranden [theories in biology didactic research: a handbook for teachers students and doctoral students] (pp. 105-116). Berlin: Springer.

Grotzer, T. A., \& Basca, B. B. (2003). How does grasping the underlying causal structures of ecosystems impact students' understanding? Journal of Biological Education, 38(1), 16-29.

Grotzer, T. A., \& Solis, S. L. (2015). Action at an attentional distance: a study of children's reasoning about causes and effects involving spatial and attentional discontinuity. Journal of Research in Science Teaching, 52, 1003-1030. https://doi.org/10.1002/tea.21233.

Hmelo-Silver, C. E., \& Pfeffer, M. G. (2004). Comparing expert and novice understanding of a complex system from the perspective of structures, behaviors, and functions. Cognitive Science, 28(1), 127-138. 
Hokayem, H., \& Gotwals, A. W. (2016). Early elementary students' understanding of complex ecosystems: a learning progression approach. Journal of Research in Science Teaching, 53(10), 1524-1545. https://oi. org/10.1002/tea.21336.

Hokayem, H., Ma, J., \& Jin, H. (2014). A learning progression for feedback loop reasoning at lower elementary level. Journal of Biological Education, 49(3), 246-260. https://doi.org/10.1080/00219266.2014.943789.

Jacobson, M. J. (2001). Problem solving, cognition, and complex systems: differences between experts and novices. Complexity, 6, 41-49. https://doi.org/10.1002/cplx.1027.

Jacobson, M. J., \& Wilensky, U. (2006). Complex systems in education: scientific and educational importance and implications for the learning sciences. The Journal of the Learning Sciences, 15(1), 11-34.

Leach, J., Driver, R., Scott, P., \& Wood-Robinson, C. (1996). Children's ideas about ecology 2: ideas found in children aged 5-16 about the cycling of matter. International Journal of Science Education, 18(1), 19-34.

Lee, T. D., Jones, M. G., \& Chesnutt, K. (2019). Teaching systems thinking in the context of the water cycle. Research in Science Education, 49(1), 137-172.

Markauskaite, L., Kelly, N., \& Jacobson, M. J. (2017). Model-based knowing: how do students ground their understanding about climate systems in agent-based computer models? Research in Science Education. https://doi.org/10.1007/s11165-017-9680-9.

Mehren, R., Rempfler, A., Buchholz, J., Hartig, J., \& Ulrich-Riedhammer, E. M. (2018). System competence modeling: theoretical foundation and empirical validation of a model involving natural, social, and humanenvironment systems. Journal of Research in Science Teaching, 55(5), 685-711.

National Research Council. (2013). Next generation science standards: for states, by states. Washington, D.C.: National Academies Press. https://doi.org/10.17226/18290.

Niebert, K., Marsch, S., \& Treagust, D. F. (2012). Understanding needs embodiment: a theory-guided reanalysis of the role of metaphors and analogies in understanding science. Science Education, 96(5), 849-877.

Orion, N., \& Libarkin, J. C. (2014). Earth system science education. In N. G. Lederman \& S. K. Abell (Eds.), Handbook of research on science education (pp. 481-496). New York: Routledge.

Piaget, J. (1966). The child's conception of physical causality. New Brunswick: Transaction Publishers.

Reiner, M., \& Eilam, B. (2001). Conceptual classroom environment-a system view of learning. International Journal of Science Education, 23, 551-568. https://doi.org/10.1080/095006901300172458.

Roth, W.-M., \& Pozzer-Ardenghi, L. (2013). Pictures in biology education. In C.-Y. Tsui \& D. F. Treagust (Eds.), Multiple Representations in Biological Education (Vol. 7, pp. 39-53). Dordrecht: Springer.

Schnotz, W. (2005). An integrated model of text and picture comprehension. In R. E. Mayer (Ed.), The Cambridge handbook of multimedia learning (pp. 49-69). New York: Cambridge University Press.

Schollum, B. (1983). Arrows in science diagrams: help or hindrance for pupils? Research in Science Education, 13(1), 45-59.

Schreier, M. (2012). Qualitative content analysis in practice. London: Sage Publishing.

Sommer, C., \& Lücken, M. (2010). System competence - are elementary students able to deal with a biological system? NorDiNa, 6(2), 125-143.

Sweeney, L. B., \& Sterman, J. D. (2000). Bathtub dynamics: initial results of a systems thinking inventory. System Dynamics Review, 16(4), 249-286.

Sweeney, L. B., \& Sterman, J. D. (2007). Thinking about systems: student and teacher conceptions of natural and social systems. System Dynamics Review, 23(2-3), 285-311.

Tsui, C. Y., \& Treagust, D. F. (2013). Introduction to multiple representations: their importance in biology and biological education. In D. F. Treagust \& C. Y. Tsui (Eds.), Multiple representations in biological education. Models and modeling in science education (Vol. 7, pp. 3-18). Dordrecht: Springer.

United Nations. (2015). Transforming our world: the 2030 agenda for sustainable development. https://sustainabledevelopment.un.org/content/documents $/ 21252030 \% 20$ Agenda $\% 20$ for $\% 20$ Sustainable\%20Development\%20web.pdf. Accessed 6 September 2018.

Publisher's Note Springer Nature remains neutral with regard to jurisdictional claims in published maps and institutional affiliations. 


\section{Affiliations}

Sophia Mambrey ${ }^{1} \cdot$ Nico Schreiber $^{2} \cdot$ Philipp Schmiemann $^{1}$

Nico Schreiber

nico.schreiber@uni-due.de

Philipp Schmiemann

philipp.schmiemann@uni-due.de

1 Faculty of Biology, Biology Education, University of Duisburg-Essen, Universitätsstraße 5, 45141 Essen, Germany

2 Faculty of Physics, University of Duisburg-Essen, Universitätsstraße 5, 45141 Essen, Germany 